\title{
Como atravessar as margens de um rio: uma entrevista com os integrantes da Periplo Compañía Teatral
}

How to cross between a river's banks: an interview with the members of Periplo Compañía Teatral

Entrevista com os integrantes da Períplo Compañia Teatral Concedida

à Jônata Gonçalves da Silva ${ }^{1}$ 


\section{Resumo}

A presente entrevista destinou-se a elencar algumas questões sobre os processos criativos e procedimentos do ofício do ator que a companhia de Buenos Aires (AR), a Periplo Compañía Teatral, realiza em suas pesquisas dentro da trajetória artística do coletivo. São perguntas que, dentre elas, abordam a importância que o grupo teve/tem para outras companhias teatrais do sul do Brasil desde a década de 1990, como é o caso da Téspis Cia. de Teatro de Itajaí. Esta entrevista serviu de aporte necessário para a complementação da dissertação de mestrado que realizei dentro do Programa de PósGraduação em Teatro na UDESC (2015 2017), onde trouxe para a reflexão conceitos e aspectos do estudo do corpo do ator tendo como objeto de pesquisa a companhia de Itajaí.

Palavras-chave: Periplo Compañía Teatral; Téspis Cia. de Teatro; ofício do ator; técnica teatral

\section{Abstract}

This interview is intended to address a few questions about the creative processes and procedures of the actor's craft that Periplo Compañía Teatral, based in Buenos Aires (AR) deals with on its researches within its artistic trajectory. These are questions that approach the importance the group has had to other southern Brazilian theater companies since the 1990s, as is the case of Téspis Cia. de Teatro, based in Itajaí (BR). This interview has served as a necessary contribution to the elaboration of the author's masters thesis, presented to the Postgraduate Program in Theater at Santa Catarina State University (UDESC) (20152017), that has brought to reflexion the concepts and aspects of the studies on the body of the actor, having the theater company of Itajai as its object of research.

Keywords: Periplo Compañía Teatral; Téspis Cia. de Teatro; actor's craft; theatrical technique 


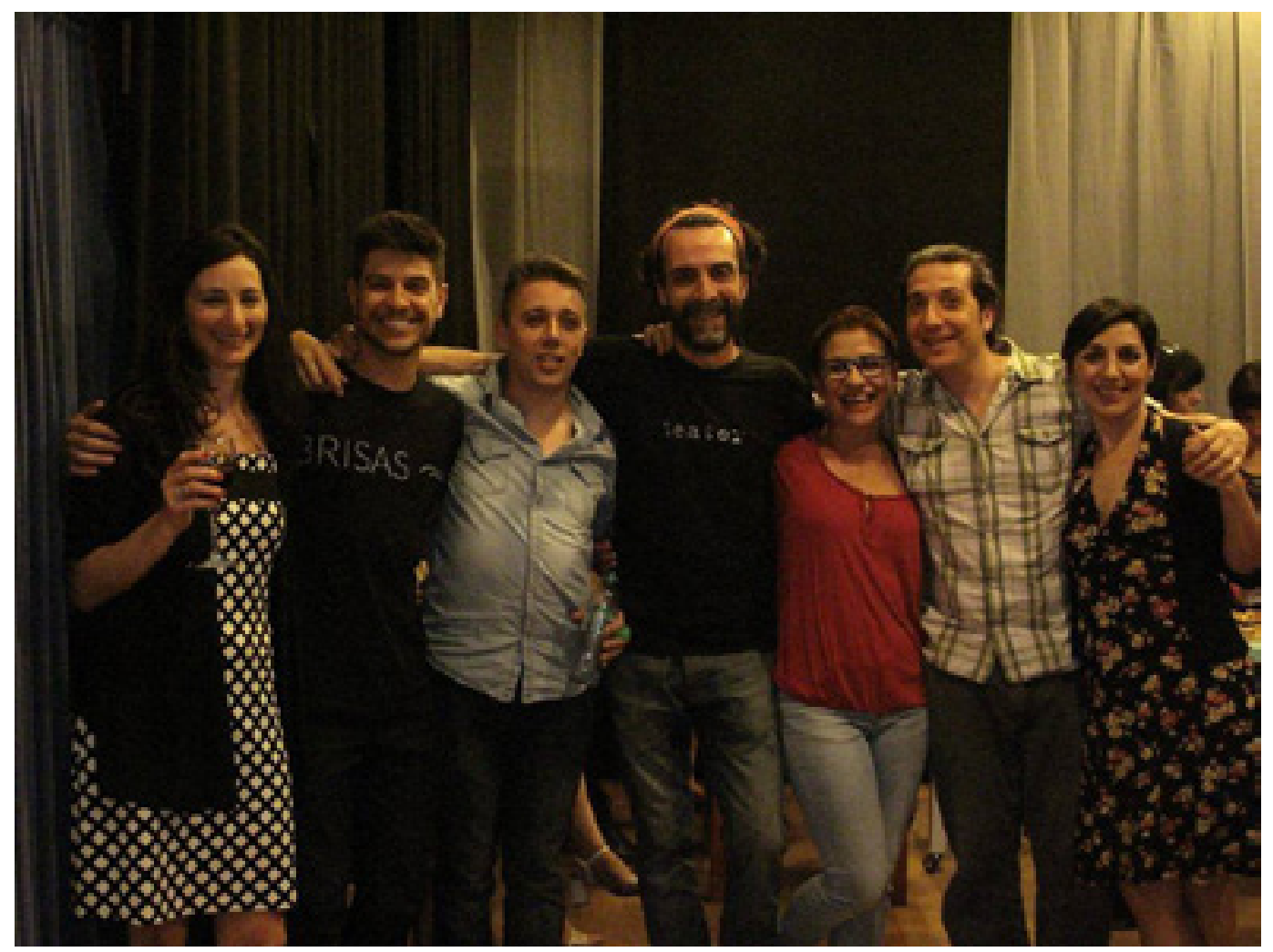

Téspis Cia. de Teatro e Periplo Compañía Teatral - da esquerda para a direta: Julieta Fassone, Jônata Gonçalves, Max Reinert, Diego Cazabat, Denise da Luz, Hugo De Bernardi e Andrea Ojeda Acervo pessoal da Períplo

A Periplo Compañía Teatral foi fundada em 1995 a partir do encontro entre alguns artistas que tinham, como objetivo primeiro, a experimentação sobre si mesmos de técnicas e conceitos preconizados por grandes mestres pesquisadores das artes cênicas. O que nascia como um espaço de estudo teatral se transformou em um coletivo que gradativamente verticalizava ainda mais sua metodologia e procedimentos para a formação do ator.

Com o tempo, a companhia começou a chamar a atenção de várias pessoas interessadas no seu processo artístico e da poética peculiar apresentada em suas montagens. $O$ que atraiu não só um público atento para assistir às peças, mas também atores/alunos interessados nos processos de construção de um pensamento distinto sobre o ofício teatral.

Sua arte não atingiu apenas a comunidade argentina, mas também a brasileira que teve a possibilidade do contato com a poética da Periplo quando os mesmos vieram para o Brasil em 1997 a fim de realizar algumas oficinas e, obviamente, apresentar suas obras. A partir desse momento muitos coletivos e artistas do sul do país migraram para a capital argentina a fim de experimentar, dentro de seminários oferecidos pelo grupo portenho, a metodologia que a Periplo utilizava em seus treinamentos e montagens. Aqui destaco o contato com a Téspis Cia. de Teatro de Itajaí que, o que antes configurava-se como uma relação de mestres e tutores, hoje em dia apresenta-se como uma afetuosa e frutífera parceria que se mantém por meio de muitos projetos realizados juntos. 
São atuais 22 anos de atividades artísticas da companhia de Buenos Aires que, desde o princípio da sua história, cruza as margens do Rio da Prata e promove o contato com a sua poética que instiga a reflexão e o debate sobre o ofício do ator.

\section{A entrevista}

A presente foi realizada, por Jônata Gonçalves da Silva, no dia 01 de dezembro de 2015. O encontro, com parte do grupo argentino, aconteceu em sua atual sede: El Astrolábio Teatro. Reuniram-se comigo: Diego Cazabat (diretor artístico da companhia), Andrea Ojeda e Hugo De Bernardi. A atriz, e também integrante da companhia, Julieta Fassone, não pôde estar presente na ocasião. Foi um momento de conversa informal, onde histórias e experiências do grupo argentino foram gentilmente compartilhadas a fim de tentar compreender melhor a peculiaridade da poética do seu trabalho.

Toda a grande história tem um início. A Periplo completou, em 2015, vinte anos de existência. Como foram os primeiros anos da Periplo? Como esse coletivo se formou?

Andrea: Na realidade, há vinte anos, o primeiro encontro foi com o objetivo de trabalhar não diretamente um espetáculo, mas sim começar a estudar e pôr em prática alguns princípios do ofício do ator. E também para nos conhecer e descobrir entre nós algo que queríamos fazer. De início entendíamos que teríamos que sistematizar algumas primeiras coisas como questões de horário, dias da semana de trabalho e, já que não tínhamos espetáculo, quais seriam os objetivos que colocaríamos para que o trabalho não se tornasse tão abstrato. Essa foi a primeira etapa: concentrar-se muitas horas a estudar, ir definindo e ver como funcionava em cada um dos atores esses princípios, esses elementos que considerávamos como fundamentais para o ator que pretendíamos ser.

Diego: Nós éramos pessoas que já vínhamos trabalhando profissionalmente com outras grupalidades e víamos que, digamos em meio geral, ou pelo sistema de produção, não favorecia certas buscas, não favorecia digamos a possibilidade de ter um tempo para desenvolver o ofício. E por outro lado uma circunstância que me parece importante é que nós não começamos trabalhando na capital federal. Nós começamos trabalhando na Grande Buenos Aires. A parte do cordão industrial em um galpão com muito frio.

Andrea: Começamos do zero! (Risos)

Diego: Não era a melhor das circunstâncias. E recordo que, inclusive, sempre que entrávamos na sala de ensaio tínhamos uma lata onde depositávamos dois pesos. E nesse momento me recordo que isso depois servia para resolver coisas, para começar a gerar alguma condição.

Andrea: A primeira produção foi uma demonstração de um trabalho técnico. 
Construímos algo que não era um espetáculo, mas era algo que tivemos a necessidade de compartilhar.

Diego: Parece-me que isso também foi a dinâmica do grupo e o que possibilitou que fossemos avançando. Começamos a ter um núcleo de pessoas que também começaram a se interessar pelo trabalho que fazíamos. E começamos a ter algumas relações de trabalho mesmo através da Periplo. Até porque algumas já tínhamos. Eu, por exemplo, já trabalhava na Escola de Arte Dramática. Andréa trabalhava no San Martín (teatro). Hugo estava terminando de se formar.

Hugo: Na Escola Municipal de Artes Dramáticas entre 1997 e 1998.

Diego: Isso! Ou seja, muita coisa já estava rolando. E foi em 1997 que estreamos o nosso primeiro espetáculo que foi - De como horbitan los hombres. Colocamos a estreia numa sala na capital o que nos foi muito bom. O primeiro seminário que fizemos, quando ainda morávamos na província, também ajudou a impulsionar, porém pensamos: vamos alugar um espaço onde a gente possa organizar uma sala de espetáculos e ter melhores condições. Nós alugamos um espaço lindo ali no Cid Campeador (região central de Buenos Aires), e lá trabalhamos por 10 anos. Um espaço que tinha a possibilidade de hospedar muitas pessoas. Muita gente por ano ia para lá estudar, viver, ensaiar e produzir. Tínhamos três salas onde fazíamos nossas apresentações e nossas temporadas. E, digamos, o trabalho da companhia foi crescendo. Começamos a viajar muito, por todo o mundo. Porém, o mais importante foi a realização dos seminários. Na verdade, o intercambio com as pessoas e a relação com grupos, como por exemplo a Téspis que é uma relação muito antiga e, realmente, uma fraternidade fora do comum.

Andrea: $\mathrm{E}$ tudo isso entendemos como parte do desenvolvimento do grupo. Inclusive estrutural também. Como por exemplo nos últimos anos deixamos de pagar aluguel e compramos um espaço próprio.

Diego: Uma autonomia. Uma independência.

Andrea: Claro! E tem a ver com um monte de coisas que vão se entrelaçando e avançando juntas. Não é conectar com alguém para fazer um espetáculo e depois desconectar. Para nós foi tudo meio seguindo, nas relações também, como ir aprendendo com o outro. Desenvolvendo algo.

Hugo: O mesmo quanto ao espaço físico do Astrolábio (nome da atual sede do grupo). Estava pensando agora que também foi uma busca de ir vendo qual necessidade de espaço tínhamos. Porque foi como disse Diego, três salas, mas antes eram duas. Depois foi a necessidade de comprimir para fazer períodos mais intensos. Digo, a morfologia de ir encontrando e entendendo um espaço físico com o trabalho de produção. Espaço coletivo também de encontro. 
Diego: Num momento para nós foi importante isso que disse Hugo, "comprimir" um pouco porque havia tanta atividade que chegou um momento que tivemos que dizer "espera". Tínhamos alguns projetos criativos e artísticos que só conseguiríamos concretizar se não tivermos tanta atividade diversificada. E isso foi um passo muito importante. De comprar esse espaço (El Astrolábio), de estar mais concentrado e de ter mais períodos de ensaio. Creio que não necessariamente alguém nos disse algo no sentido de que somos um grupo. Não é que isso define uma coisa. Um grupo para quê? Um grupo de quê? Sempre nos interessou poder vincularmos com pessoas que, bom, respeitávamos muito, mas também que de alguma maneira estão desenvolvendo um certo nível de independência à sua maneira no terreno da arte. Sem depender de certas circunstâncias permanentemente do mercado e em função disso o nosso espaço foi se adaptando.

\section{Existem apoios na Argentina que auxiliem as formações de grupos? Como a Periplo se mantém financeiramente?}

Diego: Aqui na Argentina existem dois institutos. Um que é da cidade e outro que é da nação. Um se chama Instituto Nacional de Teatro e o outro é o Pró-Teatro que dão apoio aos grupos independentes ou às salas independentes.

Andrea: Pense que são muitos, hein?!

Diego: Muitos! Estamos falando de muitíssimos espaços. Há um apoio dos dois institutos ao Astrolábio Teatro. Que é um apoio entre 15\% e $20 \%$ do gasto real. É super regulamentado! Eles inspecionam as condições de segurança do espaço e isso te habilita poder pedir o apoio. Depois há apoios para as produções que quando alguém vai realizar uma obra pede 100 e eles lhe dão 20. Quero dizer, não é que são apoios que não te resolvem nada. Bom, com certeza a gente pede porque nos parece que são nossos...da comunidade teatral.

Andrea: E privados não há aqui. Ou quando tem é muito pouco. A lei de mecenato me parece que não funciona muito bem.

Hugo: Me parece que ela não é muito acessível. Então fica quase impossível de implementar.

Diego: Não está funcionando ou, pelo menos, não como a gente entende como funciona no Brasil. Mas bom, em definitivo, o apoio que advém para a atividade teatral independente de Buenos Aires e para a Nação está bom! Para nós é muito importante ter ele. Nos ajuda a resolver algumas coisas.

Andrea: Sim, e também outras produções. Como por exemplo: as produções que fazemos com outros artistas ou estudantes. Então nos concentramos e isso é parte de um trabalho que depois nos ajuda a concretizar outros projetos. 
Diego: Ou produções para fora, ou direções para outros atores daqui inclusive.

Andrea: E depois, na verdade, investindo muito. Como por exemplo, compramos esse espaço (atual Astrolábio), e isso não quer dizer que seja um projeto de vida porque você não tem nada mais. Mas sim, porque realmente desenvolvendo isso virá um monte de outras coisas para seguir desenvolvendo. Ir assumindo alguns desafios que tem a ver com caminhos mais longos para chegar em algum lugar. Bom, e uma vez que chegamos já teremos outras coisas para pensar.

Diego: Depois eu creio também que o grupo, a companhia, é feita de pessoas muito diferentes. Que as vezes temos intenções diferentes e necessidade também diferentes. $O$ trabalho também vai te convidando a desenvolver determinadas coisas que não são só determinadas linhas ou aspectos criativos, mas sim espaços de desenvolvimento individuais. Desenvolvimento de uma ideia, de um trabalho, de uma pulsão individual. Por exemplo, o Astrolábio neste momento me parece um espaço de desenvolvimento de projetos bastante diversos. As direções que Andrea realiza, ou mesmo o Hugo, são buscas distintas e achar que isso não segue um formato original da companhia é ridículo. Do contrário, isso não se chamaria grupo, se chamaria seita.

Andrea: Sim, tratar de abrir a discussão, de falar. Porque as vezes um não sabe o desejo que o outro tem. Tentar voltar a reconhecer o outro, abrir espaços para que esses desejos brotem.

Diego: Sim, e isso tem a ver com "a criação coletiva". Sim, toda a criação é coletiva. Por isso nós necessitamos de mais tempo. Para mim me interessa dirigir, quando me interessa dirigir, com esses aportes concretos e reais onde há um momento onde tudo parece querer ser contraditório. Então necessita tempo para destilar-se. Para convencer-se ou convencer.

Como inicia sua trajetória pelo Brasil? E como se deu o contato com a Téspis Cia. de Teatro?

Diego: Foi em 1997. O primeiro brasileiro que nos chegou foi o professor André Carreira da UDESC, que vivia aqui em Buenos Aires e nos conhecemos num congresso. Bom, ele nos convidou para dar um seminário de duas semanas na própria UDESC o qual foi muito interessante. Na sequência, Carreira nos sugeriu uma ida para a cidade de Itajaí para ministrar o mesmo seminário para o pessoal, da época, da Associação Itajaiense de Teatro. Foi aí que conheci a Téspis Cia. de Teatro (Denise da Luz e Max Reinert), e também outras pessoas. E me recordo que foi aí que fui conversar com Rute Zendron, que era a diretora artística do Festival Internacional de Teatro Universitário de Blumenau naquele período. Ela disse que tinha visto o nosso trabalho num vídeo e nos convidou para apresentar - De como horbitan los hombres no Festival. Viajamos para outros lados do mundo, mas o Brasil sempre foi para nós como o nosso segundo país. 
Andrea: Sim! E tem coisas lindas, como a Téspis que completou 20 anos e nos convidaram para a sua programação de comemoração na cidade. A Cia Carona de Teatro (Blumenau) que também tive a oportunidade de estar lá nas comemorações de 20 anos de grupo. Fomos desenvolvendo juntos e passando por momentos muito distintos. É como seguir num desenvolvimento próprio e ver o outro se encontrando também. Como vão realizando as mudanças de formas...e isto está ótimo!

Diego: E depois como a gente também vai mudando, não? Porque são 20 anos e a gente mudou muito! Como projetos mais ambiciosos ou coproduções. Uma qualidade de relações que são mais maduras artisticamente também. São realmente intercâmbios mais fortes. Independentemente que a gente tenha viajado para outros lugares isso se desenvolveu com a relação com o Brasil.

Bom, e da mesma forma que vocês foram, outros também vieram para cá, não é?

Andrea: Do Brasil veio muita gente, na verdade. Muitos estudantes que depois víamos ano após ano.

Sim, houve seminários só para brasileiros também, não foi?

Diego: Sim, sim! Num momento houve só para brasileiros. E isso foi muito interessante.

Andrea: Também tivemos um seminário lá no Brasil que quem organizou foi a Téspis Cia. de Teatro no antigo espaço deles.

Hugo: Outra coisa importante de se falar é sobre a Mostra Internacional de Teatro de Grupos. Um evento que nos demandou estar muito concentrado e conectado com os grupos que iriam para Itajaí e totalmente conectados com a Téspis por conta da logística.

Diego: Eu, quando penso, há algumas cidades que são nosso segundo bairro, entende? Eu gosto de andar por Itajaí, eu gosto de andar por Santa Catarina, eu gosto de andar pelo Brasil. Porque sinto que eu o conheço um pouco. E eu gosto de seguir por aí. Eu gosto muito! Eu desfruto!

Aproveitando esse gancho da Mostra Internacional de Teatro de Grupo, foi por conta desse contato que vocês começaram a trabalhar também junto da organização do evento, não foi? Vocês acabaram fazendo a curadoria internacional da Mostra, é isso?

Diego: Recordo que nós estávamos num circuito pelo Brasil e passamos por Itajaí no momento que acontecia a Mostra Itajaiense de Teatro e nos pareceu interessante o que estava passando pelo movimento teatral local. Havia algo que, digamos, não estava contaminado no sentido de seguir certas linhas estabelecidas, naquele 
momento, dentro da produção teatral. Nós apresentamos nosso espetáculo lá e enfim, a relação com a Téspis se tornou mais intensa.

Andrea: Em algum momento ocorreu da gente conversar com a Téspis sobre o quão bom seria trazer alguns grupos de fora do Brasil para a Mostra.

Diego: Na verdade eles realizavam um trabalho impressionante de produção. Impecável em termos de logística, alojamento, transporte, teatro e a gente aproveitava quando viajava para distintos festivais para Venezuela, EUA e Europa, por exemplo, e realizávamos os contatos.

Andrea: Sabe o que eu penso? Que se fosse agora essa mostra também seria outra história. Na verdade, éramos todos muito imaturos. Hoje eu penso que a Mostra foi uma coisa muito audaz. Me recordo que para nós era um compromisso de estarmos lá concentrados em elaborar a Mostra da melhor maneira

Hugo: Sim, e eu me lembro que a dificuldade da logística era muito grande. Digo, a internet não era algo tão acessível. Poucos tinham e-mail.

Andrea: Resolvíamos muitas coisas por fax, por exemplo. (Risos)

Bom, falando agora um pouco sobre as criações da Periplo, como inicia o processo criativo de uma obra? O grupo usa a ferramenta da improvisação para levantar material criativo? O que a companhia entende por improvisação dentro desse período de criação?

Andrea: Bom, em alguns muito raros momentos os trabalhos da Periplo iniciam com um texto escrito. Um texto dramático, digo. $E$ isso já possibilita para o grupo um outro espaço de busca. Portanto, cada procedimento de montagem de um espetáculo se torna muito distinto do outro apoiando-se, de início, em alguns temas provenientes da filosofia, literatura ou até mesmo da física. Através de propostas práticas são provocados, nos atores, o exercício de levantar material cênico. O que penso também é que como nós realmente dedicamos muito tempo para um treinamento que foi se reformulando, mas desde o início tinha a ver muito com a construção da ação, isso nos possibilita poder assumir, quando começamos um processo de um espetáculo, de não estar tão preocupados com a história, senão tentar colocá-la como uma ação. E ir desenvolvendo, de distintas maneiras, com distintas consignas, um trabalho que, obviamente é sistemático.

Andrea: E sobre a improvisação, é uma ferramenta que nós utilizamos muito no treinamento, por exemplo. Sobre certos princípios poderíamos ficar improvisando horas em sala de ensaio. Porém, sabendo que esse trabalho não será meramente físico, mas sim como essa improvisação gera uma transformação real e concreta no tempo. 
Diego: Se improvisa tendo que passar por determinados lugares muito claramente ou tendo consciência de alguma coisa. Porque as vezes pode-se entender a improvisação como poder fazer qualquer coisa. Para nós nos importa principalmente a construção desse presente cênico. Sempre trabalhamos na obsessão dessa relação da precisão e espontaneidade. Qualquer espetáculo nosso, creio, tem uma busca sobre a precisão muito clara. E quando conseguimos isso a improvisação começa a entrar em um outro nível. Que é o nível do presente puro. O primeiro que se tem de fazer é tratar de ter uma conexão diferente do que o habitual com o que te rodeia. Nós sempre buscamos no nosso treinamento uma presença do ator que não seja cotidiana. Tudo que fizemos foi para encontrar ferramentas para transformarmos. Para dimensionar esse espaço como um lugar onde se pode criar uma outra realidade. $E$ entendendo que quem pode criar uma outra realidade é o ator, com a sua transformação e com sua ação.

\section{O que seria esse binômio "precisão e espontaneidade"?}

Diego: O orgânico, eu creio. O preciso é algo que acontece num momento justo e num lugar justo. E o espontâneo se pode definir através da mesma concepção. No geral eu creio que se toma o conceito da precisão como um elemento mecânico. Uma máquina é exata, mas a precisão é orgânica. Está vinculada a outra coisa, está no presente. A dimensão está na ação, que não é mecânica. E quando a dimensão da ação se define, se incorpora, não se pensa mais na ação. Ela ocorre.

Andrea: Nós, por um momento muito grande do nosso trabalho, agíamos com precisão para racionar, entender e pôr a ação ao máximo em diálogo. Então, éramos obsessivos e parecia que o espontâneo ficava mais longe, em princípio. Porque é um exercício de entender que há algo por algo. E creio que isso nos deu o exercício de entender que a liberdade custava. Digamos que ser livre dentro dessa estrutura necessitava uma flexibilidade interna infernal. E aí começamos em uma outra etapa. Como liberávamos uma coisa que para nós era linguagem? Necessitávamos ter essa precisão, mas como se dava nisso uma libertação? A sensação de liberdade, de sentir a forma e superá-la.

Diego: Tem uma coisa que é importante reafirmar que não é a precisão do movimento. É a precisão das ações. Entendendo que a ação é algo distinto do movimento.

Andrea: E quando isso acontece para mim a ação golpeia com toda a intensidade que a ação tem. Muito mais transformadora. E nesse momento eu penso: o ofício tem sentido. Digo, para mim faz sentido porque me revela coisas. Que me faz olhar para o outro como eu nunca olhei. Me carrega de potência e energia para seguir desenvolvendo nessa busca.

Diego: Bom, isso é ofício! Para mim a precisão aparece quando a forma explode. E a forma explode não quer dizer que ela se destrua, mas sim que se ilumina. Mas, 0 que é bom de entender é que essa precisão e espontaneidade é um trabalho de aproximação que se alcança depois de muito suor. 
Andrea: Isso! Mas também é importante dizer que isso tudo serve para àquilo que nós buscamos, para o tipo de linguagem, para o que a gente entende do ofício e com a nossa maneira de construir.

Dentro da academia debatemos muito sobre a questão da técnica do ator. Alguns defendem que a técnica possibilita que o ator esteja mais flexível nos processos de criação. Outros falam que a técnica também poderia engessar o ator. Como que a Periplo entende, define e trabalha com essa questão?

Diego: Me parece que é o mesmo que acontece com um pianista, ou um violinista, ou um guitarrista, quando começa. Ou seja, a única maneira de superar a técnica é meter-se na técnica. Porque se você quiser fazer um trabalho técnico em três meses e querer estar liberado disso estais equivocado. Totalmente! Para qualquer disciplina e ofício. Se você quiser ser carpinteiro em três meses estais enganado. Porque há ferramentas que as usaste pouco ou sabes pouco como usá-las. Se você quiser ser um pianista em três meses e em três meses trabalhas 10 horas por dia não vais conseguir. Porque não é um processo de acúmulo de horas. É um amadurecimento distinto.

Andrea: Para mim, o que parece, é que alguns atores têm um processo técnico muito íntimo. Não podemos confundir. Todos somos diferentes. Então eu creio que o pior é o ator que não dialoga consigo mesmo. Porque há pessoas que creem que fazem um trabalho técnico só porque fazem um trabalho psicofísico e, na verdade, depois na cena isso não resulta.

Hugo: Estava pensando também que a técnica tem a ver em como você vai atando as visões que tens. Como, por exemplo, imaginas algo. E agora? Como eu faço para realizar isso?

Andrea: Nós, por exemplo, somos atores criativos. Ligando ao o que o Hugo falou. Usar a técnica para criar algo. Então aí necessitamos, na verdade, certos tipos de treinamento, seguir desenvolvendo esse treinamento e agregar elementos.

Diego: Na verdade tudo está ligado a uma coisa imediata. Alguém, de um dia para o outro, fica famoso ou qualquer um pode atuar e dirigir hoje em dia. Qualquer um pode ser tudo! Bom, me parece ótimo que realmente qualquer um pode ser tudo em termos de liberdade social. Como eu estaria contra isso? Estou de acordo! Mas me parece que também se custa muito aceitar as atividades que necessitam e requerem sistematização. Insistência de algum tipo.

No livro que vocês publicaram Teatro: misterios de un oficio poético (2011), alguns conceitos norteadores para o trabalho do ator são apresentados através de relatos de experiências aplicadas em seus próprios processos. De acordo com o livro a companhia acredita que o trabalho sobre o corpo do ator não é só um trabalho sobre suas habilidades físicas, mas através de muito treinamento, o corpo alcança o título de portador de tempo e ritmo. Ou seja, os atores são realizadores e criadores 
de realidades provisórias. São provocadores ao instigar um trabalho sobre si mesmo, e que resulte numa busca pela autonomia artística. "Portadores de tempo e ritmo"? "Criadores de realidades provisórias"? Poderiam explicar um pouco sobre isso?

Diego: O teatro como o lugar aonde se cria a realidade. Realidade essa que não é a única, cotidiana e por isso é uma realidade à parte. Não é que há algo que se está ilustrando.

Andrea: Temos uma série de clichês e necessidades para vincularmos com o cotidiano que são os que nos dão algumas liberdades e, também, nos prendem. Então isso levado para a cena, que é um espaço de comportamento distinto, se torna um lugar muito fértil que você tem que confrontar. Porque abaixo, ou ao lado daquilo que você construiu há outra coisa. Abaixo das tensões que se mostram, seguramente há outros lugares e outras coisas onde a vida está suspensa. E a gente trabalha muito nisso: o que havia por detrás daquilo que primeiro aparecia no treinamento.

Diego: E depois o teatro não como reprodutor da realidade, mas sim como criador da realidade autônoma, nova e, obviamente, com alguma relação. O ator encontra outro tempo e ritmo para criar suas realidades. $O$ que nós buscamos com o nosso teatro é romper com essa realidade social.

Hugo: Uma coisa que eu estava pensando ainda sobre essa questão do tempo e ritmo é que se eu não sou portador desse tempo e ritmo eu sou o que? Há alguma inquietude? Há uma certa conformidade?

Andrea: Certa pressão também. Porque se não é teu próprio tempo e ritmo de quem é? Há também uma situação de tensão.

E sobre o treinamento físico! Eu soube que no início da sua trajetória o grupo mantinha horas e horas a fio na sala de ensaio realizando exaustivos treinamentos físicos. $O$ que era igualmente realizado em seus seminários. Hoje, pelo que eu pude perceber no seminário que participei no início desse ano, esse treinamento está mais diluído dentro do processo criativo da obra. Algumas coisas mudaram? Essa mudança é real ou é só uma impressão minha? O que mudou? E o que vocês pensam sobre a questão do treinamento?

Andrea: Teve um momento que foi necessário quebrar o corpo para esculpir a verdade. $E$ isso tinha a ver com o nosso treinamento que era chegar a certo estado de repetição, de baixar defesas, que acabou se reformulando no nosso trabalho de uma maneira que, creio, foi amadurecendo. O que penso que se dava com as pessoas que viam fazer os seminários, e isso nós fomos mudando, se sentia que estavam fazendo um grande trabalho porque realmente suavam muito (risos), transpiravam e era um trabalho que a gente fazia conscientemente para isso. Era um trabalho para entrar num outro nível de registro. E muitas vezes encontramos que um outro tipo de intervenção também gerava um outro amadurecimento no vínculo. 
Diego: E eu creio que nos últimos seminários encontramos ótimos resultados. Talvez se transpire menos, mas se aprende mais. E há um treinamento que é o treinamento do ator. Bom, se você deixar de fazer por muito tempo coisas que the são necessárias você pode perde-las. E depois há também alguns exercícios específicos para conseguir determinadas coisas.

Andrea: Eu penso também que o nosso processo, e dos nossos estudantes, era provar mais diretamente o que nós mesmos estávamos trabalhando. Entender também que essa nossa obsessão era para o nosso trabalho artístico.

Há muito tempo a dramaturgia era, na verdade, algo que se restringia ao texto dramatúrgico. Hoje em dia lê-se esse conceito de uma forma ampliada e reconhecemos a dramaturgia no espaço, na luz, no corpo. No trabalho de vocês eu percebo essa dramaturgia fortemente construída dentro de um trabalho corporal. $O$ que vocês poderiam falar sobre essa dramaturgia corporal que vocês sustentam em cena?

Andrea: $O$ que eu penso da dramaturgia do ator é que ela se dá quando o ator se transforma. Há uma transformação que constrói essa dramaturgia. Que faz aparecer algo novo que jamais poderá voltar a ser igual nesse espaço presente. Certos graus de transformação concretados jamais voltarão a ser iguais. É um grau de transformação que conta algo.

Diego: Para mim parece que o corpo no nosso teatro, para colocar algumas das nossas dramaturgias na cena, são indissociáveis de certos níveis físicos e corporais. Por vezes me parece que as dramaturgias textuais mais clássicas, e isso não lhe digo pejorativamente, são mais aristotélicas digamos assim. Há algo que já está salvo que é quando você entende quando alguém está invocando as bruxas (fazendo referencia a Macbeth). Tudo bem, eu entendo que você está invocando as bruxas, mas o problema do teatro não é entender que você está invocando as bruxas. O problema do teatro é invocar as bruxas! Fazê-lo! E como se invoca as bruxas? Você nunca viu. $O$ que eu the asseguro é que com essa energia cotidiana você nunca vai conseguir. $O$ que eu the asseguro é que com esse corpo cotidiano não vai acontecer. Um professor meu me dizia que o mistério é como um poço que não tem fim. E que a única coisa que você tem que fazer é se jogar, mas você não vai chegar nunca no final desse mistério. $O$ trabalho do ator é isso!

Recebido em: 21/10/2017

Aprovado em: 21/10/2017 